\title{
Costs and cost-effectiveness of full implementation of a biennial faecal occult blood test screening program for bowel cancer in
}

\author{
Australia
}

\author{
Michael P Pignone, MD, MPH ${ }^{1}$ [Professor, and Chief of General Medicine and Clinical \\ Epidemiology], Kathy L Flitcroft, BBSc, MA(Govt) ${ }^{2}$ [GradCertHlthPolicy, Research Fellow \\ (Health Policy), Screening and Test Evaluation Program], Kirsten Howard, MPH, MHIthEc, \\ $\mathrm{PhD}^{2}$ [Associate Professor, Health Economics], Lyndal J Trevena, MB BS, MPhilPH, \\ $\mathrm{PhD}^{2}$ [Associate Professor, Associate Dean (International), and Director, Office for Global \\ Health], Glenn P Salkeld, MPH, PhD²[Professor and Head of School], and D James B St \\ John, MD, FRACP, AGAF ${ }^{3,4}$ [Associate Professor and Honorary Principal Fellow, and \\ Honorary Senior Associate] \\ ${ }^{1}$ Lineberger Comprehensive Cancer Center, Cecil G Sheps Center for Health Services Research, \\ University of North Carolina at Chapel Hill, Chapel Hill, NC, USA.
}

2Sydney School of Public Health, University of Sydney, Sydney, NSW.

${ }^{3}$ Department of Medicine (Royal Melbourne Hospital), University of Melbourne, Melbourne, VIC.

${ }^{4}$ Cancer Council Victoria, Melbourne, VIC.

\section{Abstract}

Objective-To examine the costs and cost-effectiveness of full implementation of biennial bowel cancer screening for Australian residents aged 50-74 years.

Design and setting-Identification of existing economic models from 1993 to 2010 through searches of PubMed and economic analysis databases, and by seeking expert advice; and additional modelling to determine the costs and cost-effectiveness of full implementation of biennial faecal occult blood test screening for the five million adults in Australia aged 50-74 years.

Main outcome measures-Estimated number of deaths from bowel cancer prevented, costs, and cost-effectiveness (cost per life-year gained [LYG]) of biennial bowel cancer screening.

Results-We identified six relevant economic analyses, all of which found colorectal cancer (CRC) screening to be very cost-effective, with costs per LYG under \$55 000 per year in 2010 Australian dollars. Based on our additional modelling, we conservatively estimate that full implementation of biennial screening for people aged 50-74 years would have gross costs of $\$ 150$ million, reduce CRC mortality by $15 \%-25 \%$, prevent $300-500$ deaths from bowel cancer, and save 3600-6000 life-years annually, for an undiscounted cost per LYG of \$25 000-\$41 667, compared with no screening, and not taking cost savings as a result of treatment into consideration. The additional expenditure required, after accounting for reductions in CRC

Correspondence: pignone@ med.unc.edu.

COMPETING INTERESTS

Michael Pignone is the recipient of a Packer Policy Fellowship from the Australian Government Department of Health and Ageing. Glenn Salkeld is involved in research funded through an NHMRC Program Grant 2006-2010, and a NSW Cancer Institute Cancer Epidemiology Grant. James St John receives a sitting fee for one or two meetings each year as a member of the Program Advisory Group and Quality Working Group for the National Bowel Cancer Screening Program, but has no involvement with financial aspects of the Program. 
incidence, savings in CRC treatment costs, and existing ad-hoc colonoscopy use, is likely to be less than $\$ 50$ million annually.

Conclusions-Full implementation of biennial faecal occult blood test screening in Australia can reduce bowel cancer mortality, and is an efficient use of health resources that would require modest additional government investment.

Colorectal cancer (CRC), also known as bowel cancer, is an important condition in Australia, with 13951 new cases and 4047 deaths from CRC recorded in 2007. ${ }^{1}$ It was estimated that over 14700 Australians would be diagnosed with CRC in 2010, and about 3700 would die from it. ${ }^{2}$ Australia has one of the highest CRC mortality rates in the world, ${ }^{3}$ and CRC is Australia's 10th most important condition in terms of disability-adjusted lifeyears lost for men and for women. ${ }^{4}$ Caring for patients with CRC is also expensive: Australia spent $\$ 235$ million in 2001 for direct medical costs of CRC; $; 5$ by 2010, expenditure was estimated to exceed $\$ 750$ million (Sumitra Ananda, Medical Oncologist, Royal Melbourne Hospital and BioGrid Australia, personal communication).

Screening has been shown in randomised trials to reduce the incidence of and mortality from CRC. ${ }^{6,7}$ Based on this evidence, many developed countries are implementing CRC screening programs. ${ }^{8}$ The Australian Government has initiated only a limited CRC screening program, with a one-time immunochemical faecal occult blood test (iFOBT) for people aged 50, 55 and 65 years. This is despite National Health and Medical Research Council (NHMRC) guidelines recommending a full program of biennial faecal occult blood test (FOBT) screening for those aged over 50 years. ${ }^{9}$ One of the main barriers to full implementation has been inadequate funding. ${ }^{10}$

Modelling offers a means of understanding the costs and potential benefits of CRC screening, and can be used to help inform decisions about program implementation. A systematic review of older models of CRC screening performed mainly in United States settings found CRC screening to be both effective and relatively good value in terms of cost per life-year gained (LYG). ${ }^{11}$ However, these models did not consistently include the costs of program administration and infrastructure or costs of achieving the assumed levels of participation and adherence. Also, older models and modelling done in other settings, such as the US or Europe, may not accurately reflect current costs in Australia.

We reviewed relevant existing modelling studies from Australia and performed additional basic modelling to provide estimates of costs and outcomes from full implementation of biennial iFOBT screening for adults aged 50-74 years.

\section{METHODS}

\section{Literature review}

We conducted keyword searches in PubMed, the United Kingdom National Health Service Economic Evaluation Database (NHS EED; http://www.crd.york.ac.uk/crdweb/) and the US Tufts Medical Center Cost Effectiveness Analysis Registry (http:// www.tufts-nemc.org/cearegistry) to identify existing modelling studies and economic analyses published since 1993. We also reviewed reference lists from published articles and sought advice from experts to locate other analyses not identified in the database searches. We focused mainly on modelling studies specific to the Australian setting, but sought other analyses for parameters or questions that have not been well studied in Australia. We considered studies that examined costs and cost-effectiveness of FOBT screening programs compared with no screening program; we did not consider analyses that only compared two or more screening methods. We standardised costs to 2010 Australian 
dollars using purchasing power parities ${ }^{12}$ and the Australian Institute of Health and Welfare Health Price Index. ${ }^{13}$

\section{Additional modelling}

We then performed additional modelling of biennial iFOBT screening for those aged 50-74 years using estimates derived from our literature review, data from the current Australian screening program, and interviews with screening program staff and Australian content experts. Our modelling assumptions are outlined in Box 1. We estimated that about five million Australians would be eligible for screening within the 50-74-years age range, leading to 2.5 million being offered iFOBT screening each year in a biennial program. We assumed that the participation rate would be $40 \%$ (based on participation in the current screening program), leading to about one million completed tests per year. ${ }^{15} \mathrm{We}$ also assumed a $75 \%$ follow-up rate after positive FOBTs, and estimated the funds required to achieve this level of adherence.

We estimated the screening program would reduce bowel cancer mortality by $15 \%-25 \%$, based on intention-to-treat analyses of biennial guaiac-based FOBT (gFOBT) randomised trials $(15 \%)^{6}$ and predicted mortality reductions with iFOBT in previous modelling studies, adjusted for expected participation $(25 \%) .{ }^{11}$ Risk reductions were applied against an estimated 2000 deaths per year attributable to CRCs that would otherwise have been detected by screening in the 50-74-years age group. ${ }^{19} \mathrm{We}$ also assumed that each CRC death prevented would be associated with an average of $12 \mathrm{LYGs}$ (literature estimates range from 10 to $14 \mathrm{LYGs}^{17,18}$ ).

We assumed an FOBT positivity rate of about 5\%, a value slightly lower than that observed in the current program, to account for effects of increased rescreening in a full screening program. Of those with positive iFOBTs, we assumed that 3\%-5\% would have cancer; $20 \%$ advanced adenomas; and 20\%-25\% non-advanced adenomas. ${ }^{12,17}$ Screening program participants supposed to have adenomas would enter a surveillance program based on NHMRC guidelines (colonoscopy every 3 years for advanced adenomas; colonoscopy every 5 years for non-advanced adenomas); those with cancer would receive appropriate treatment and surveillance. ${ }^{9}$

In the base case, we assumed no treatment cost offsets from screening compared with usual care. We then examined likely cost offsets resulting from decreased CRC incidence and a shift to CRC detection at an earlier cancer stage as a result of screening, using newer estimates of the cost of CRC care. $^{20}$

Costs were based on estimates from other modelling studies, current program costs, and our own estimates of the program activities, such as ensuring adherence. We included estimates of program administrative costs, including general administration, promotion of participation in screening, adherence support for those undergoing colonoscopy, and the costs of programs to reduce health disparities or inequity. We assumed information technology improvements and quality assurance efforts were included in general administrative costs. We assumed each colonoscopy cost $\$ 1300$, including the cost of polypectomy and pathology tests for the $40 \%-50 \%$ of cases in which polyps are detected. Cancer treatment costs would be accounted for through the usual care system, as is the case currently.

Because we were concerned with developing better estimates of immediate program costs and health impact, we did not discount either the benefits or costs of the screening program. In addition, we did not account for patient-related factors such as patient time costs, ${ }^{21}$ differences in quality of life, or productivity losses. Previous estimates suggest that the costs 
associated with lost productivity attributable to CRC may be large $;{ }^{5}$ however, both including productivity losses in economic evaluation, and the methods used to estimate them, remain controversial.

1 Modelling assumptions, required resources, costs and cost-effectiveness

\section{Assumptions about participation and adherence}

- 5 million average-risk Australians aged 50-74 years*

- 2.5 million would be offered screening each year (biennial screening)

- 1 million would accept based on a $40 \%$ participation rate $\dagger$

- $5 \%$ positive findings in the established program, $¥$ leading to 50000 positive tests per year

- $\quad 75 \%$ adherence to colonoscopy (with adherence support as below), leading to 37 500 initial diagnostic colonoscopies per year

- $20 \%-25 \%$ of colonoscopies will find large adenomas or cancer§

- $20 \%-25 \%$ of colonoscopies will find smaller, non-high-risk adenomas

- $\quad 15$ 000-20 000 Australians will enter the surveillance colonoscopy programII

- 75000 colonoscopies each year total for program, based on 37500 new diagnostic and 37500 surveillance examinations per year

\section{Assumptions about mortality reduction}

- $15 \%-25 \%$ reduction in colorectal cancer mortality across the population**

- 12 life-years saved per death prevented $\dagger \dagger$

\section{Cost assumptions}

- General program administrative costs, $\$ 5.0$ million

- 2.5 million initial mailings per year at $\$ 4$ each, $\$ 10.0$ million

- 1.5 million reminder letters at $\$ 0.67$ each, $\$ 1.0$ million

- 1 million test processing fees at $\$ 25$ per test, $\$ 25.0$ million

- 40000 primary care visits at $\$ 35$ each, $\$ \$ \$ 1.5$ million

- Improving participation and adherence, $\$ \S \$ 10.0$ million

- 75000 colonoscopies at $\$ 1300$ per test, inclusive, III $\$ 97.5$ million

* Based on demographic statistics as in Bishop et al 2008. ${ }^{14} \dagger$ Based on faecal occult blood test screening program to date. ${ }^{15} \ddagger$ Assumption based on expected decrease in positive findings with ongoing screening. § Based on faecal occult blood test screening program to date. ${ }^{15,16}$ II Estimate based on National Health and Medical Research Council recommendations with incomplete adherence. ${ }^{9 * *}$ Based on estimates from other models and trials, adjusted to participation..$^{6,11} \dagger \dagger$ Average of estimates from Burnet et al $2005^{17}$ and the United States National Cancer Institute. ${ }^{18}+\neq$ Assumption that $80 \%$ of patients with a positive test (likely to be fewer) will see a general practitioner, with $\$ 35$ being the estimated cost of reimbursement for GP visit. ${ }^{15} \S \S$ Estimate based on expenditures in the current faecal occult blood test screening program. IIII Estimated price similar to weighted average of prices used in Bishop et al 2008. ${ }^{14}$ 


\section{RESULTS}

\section{Literature review}

We identified six analyses performed specifically to evaluate the costs and costeffectiveness of screening for bowel cancer in Australia (Box 2). ${ }^{14,22-26}$ Each found that screening was effective in reducing CRC mortality, with costs per LYG compared with no screening usually less than $\$ 50000$. Three models estimated total annual program costs, ranging from $\$ 39$ million ( $\$ 56$ million in 2010 dollars) for biennial gFOBT screening of people aged 55-69 years to $\$ 140$ million ( $\$ 178.5$ million in 2010 dollars) for biennial gFOBT screening of people aged 50-85 years. ${ }^{23,25,14}$ Existing models all assumed relatively low treatment costs for advanced CRC, and most did not include costs of ensuring colonoscopy adherence.

\begin{tabular}{|c|c|c|c|c|c|c|c|}
\hline \multicolumn{7}{|c|}{2 Modelling studies of bowel cancer screening in Australia } & \\
\hline $\begin{array}{l}\text { Currency } \\
\text { used }\end{array}$ & $\begin{array}{l}\text { Screening } \\
\text { strategies } \\
\text { evaluated }\end{array}$ & $\begin{array}{c}\text { Program } \\
\text { participation }\end{array}$ & $\begin{array}{l}\text { Follow-up after } \\
\text { positive FOBT }\end{array}$ & $\begin{array}{c}\text { Estimated } \\
\text { cost per } \\
\text { life-year } \\
\text { gained } \\
\text { compared } \\
\text { with no } \\
\text { screening* }\end{array}$ & $\begin{array}{c}\text { Colonoscopy } \\
\text { costs/polypectomy }\end{array}$ & $\begin{array}{l}\text { Total annual } \\
\text { screening } \\
\text { costs* }\end{array}$ & $\begin{array}{l}\text { Treatment costs by } \\
\text { cancer stage } *, \dagger\end{array}$ \\
\hline $1994 \mathrm{~A} \$$ & $\begin{array}{l}\text { Annual } \\
\text { gFOBT, } \\
\text { ages 50- } \\
80 \text { years }\end{array}$ & $\mathrm{nr}$ & $83 \%$ & $\begin{array}{c}24660 \\
(\$ 36317)\end{array}$ & $\$ 800(\$ 1178)$ & $\mathrm{nr}$ & $\begin{array}{l}\text { A: } \$ 14909 \text { (\$21956) } \\
\text { B: \$16 } 183(\$ 23833) \\
\text { C: } \$ 16372(\$ 24111) \\
\text { D: \$20 } 499 \text { (\$30189) }\end{array}$ \\
\hline $1996 \mathrm{~A} \$$ & $\begin{array}{l}\text { Biennial } \\
\text { gFOBT, } \\
\text { ages 55- } \\
69 \text { years }\end{array}$ & $66 \%$ & $\mathrm{nr}$ & $\begin{array}{l}\$ 12000 \\
(\$ 17192)\end{array}$ & $\$ 1000(\$ 1433)$ & $\$ 39 \mathrm{M}(\$ 56 \mathrm{M})$ & $\begin{array}{l}\text { A: } \$ 14000(\$ 20058) \\
\text { B: } \$ 14000(\$ 20058) \\
\text { C: } \$ 22000(\$ 31519) \\
\text { D: } \$ 19000(\$ 27221)\end{array}$ \\
\hline $2001 \mathrm{~A} \$$ & $\begin{array}{l}\text { Biennial } \\
\text { gFOBT, } \\
\text { ages 55- } \\
64 \text { years }\end{array}$ & $60 \%$ & $\mathrm{nr}$ & $\begin{array}{l}\$ 41183 \\
(\$ 53883)\end{array}$ & $\$ 897 / \$ 1325(\$ 1174 / \$ 1734)$ & $\mathrm{nr}$ & $\begin{array}{l}\text { A: \$15 } 318(\$ 20042) \\
\text { B: \$29 } 804(\$ 38995) \\
\text { C: \$23 } 021(\$ 30120) \\
\text { D: \$ } 5596(\$ 7322)\end{array}$ \\
\hline $2002 \mathrm{~A} \$$ & $\begin{array}{l}\text { Biennial } \\
\text { gFOBT, } \\
\text { ages 50- } \\
85 \text { years }\end{array}$ & $100 \%$ & $100 \%$ & $\begin{array}{c}\$ 39459 \\
(\$ 50320)\end{array}$ & $\$ 578 / \$ 854^{\S}(\$ 1024 / \$ 1512)$ & $\$ 140 \mathrm{M}(\$ 178.5 \mathrm{M})$ & $\begin{array}{l}\text { Early: } \$ 15718^{\S}(\$ 31277) \\
\text { Late: } \$ 13483^{\S_{(\$ 26829)}}\end{array}$ \\
\hline $2004 \mathrm{~A} \$$ & $\begin{array}{l}\text { Biennial } \\
\text { iFOBT, } \\
\text { ages } 50- \\
74 \text { years }\end{array}$ & $45 \%$ & $55 \%$ & $\begin{array}{c}\$ 36080 \\
(\$ 43445)\end{array}$ & $\$ 1082 / \$ 1606(\$ 1303 / \$ 1934)$ & $\$ 130 \mathrm{M}(\$ 156.5 \mathrm{M})$ & $\begin{array}{l}\text { A: \$17 } 148(\$ 20649) \\
\text { B: \$33 } 364(\$ 40175) \\
\text { C: \$25 } 771 \text { (\$31032) } \\
\text { D: \$6 } 264(\$ 7543)\end{array}$ \\
\hline $2010 \mathrm{~A} \$$ & $\begin{array}{l}\text { Biennial } \\
\text { iFOBT, } \\
\text { ages 50- } \\
74 \text { years }\end{array}$ & $40 \%$ & $75 \%$ & $\begin{array}{l}\$ 25000 \text { to } \\
\$ 41667\end{array}$ & $\$ 1300$ & $\begin{array}{c}\text { Gross, } \$ 150 \mathrm{M} \\
\text { Net, } \$ 96 \mathrm{M}\end{array}$ & $\begin{array}{l}\text { A: } \$ 30890 \\
\text { B: } \$ 47354 \\
\text { C: } \$ 74225 \\
\text { D: } \$ 61423\end{array}$ \\
\hline
\end{tabular}


$\mathrm{gFOBT}=$ guaiac-based faecal occult blood test. $\mathrm{iFOBT}=$ immunochemical faecal occult blood test. $\mathrm{M}=$ million. $\mathrm{nr}=$ not reported.

Original analysis cost, with cost standardised to 2010 Australian dollars in parentheses.

${ }^{\dagger}$ Stages A, B, C and D according to the Dukes classification.

*Using data from Bolin et al 1999.26

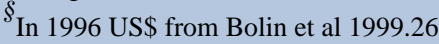

\section{Additional modelling}

Our model estimates that among one million annual participants, 50000 would have positive iFOBTs each year, with 37500 going on to have colonoscopies. In addition, about 37500 surveillance colonoscopies will be required annually, giving a total of 75000 colonoscopies per year.

The estimated gross costs of a biennial iFOBT-based program for those aged 50-74 years were about $\$ 150$ million per year. The largest single component ( $\$ 97.5$ million) is the cost of diagnostic and surveillance colonoscopies. The costs of mailing invitations, reminder letters, processing iFOBTs, and returning iFOBT results would be about $\$ 36$ million per year. About $\$ 15$ million would be budgeted for program administrative costs, including general administration ( $\$ 6$ million), promoting program participation ( $\$ 3$ million), reducing inequity (\$3 million) and ensuring adherence after positive FOBT results (\$3 million).

Our modelled screening program would be expected to reduce mortality from bowel cancer by $15 \%-25 \%$, resulting in 300-500 fewer deaths from CRC per year, or 3600-6000 lifeyears saved. The undiscounted cost per LYG of screening is estimated to be $\$ 25000-\$ 41$ 667 , consistent with other models we reviewed.

\section{Net costs and additional investment}

Our estimates of total program cost and those in the other analyses we reviewed are likely to be conservative for several reasons. First, they do not account for the ability of screening to prevent bowel cancer. The Minnesota trial of gFOBT screening found a $17 \%$ reduction in CRC incidence with extended follow-up. ${ }^{27}$ Based on the use of iFOBT and on our assumptions about participation, it may be reasonable to expect a $10 \%$ reduction in incidence in the Australian population aged 50-74 years, or 900 fewer cases per year. If we assume $\$ 50000$ in treatment cost savings per case prevented based on newer costs of cancer care,$^{20}$ annual savings could be as high as $\$ 45$ million. Even conservatively assuming a $5 \%$ reduction in incidence would save $\$ 27$ million.

Second, cost offsets from the more favourable distribution of cancer stage with screening have not been incorporated in previous models. Accurately accounting for this effect will be particularly important in the context of rapidly rising costs of treating patients with advanced bowel cancer. ${ }^{20,28}$ Screening reduces the proportion of people with metastatic disease at diagnosis from $18 \%$ to $3 \%$, and increases the proportion of those with local disease (Dukes Stage A) from $17 \%$ to over $40 \% .{ }^{29}$ A $10 \%$ conversion of cancers from advanced disease to local disease could be expected to save $\$ 27$ million (900 cases at $\$ 30000$ per case) each year. Estimates from the Dutch modelling group, using US cost data, suggest that FOBT screening would become cost-saving (savings from treatment costs would exceed investment in screening) within 25-30 years, given changing treatment patterns and costs. ${ }^{20}$

In addition, the actual incremental government expenditures required for full implementation are also likely to be lower, because many adults in the screening age range have already had colonoscopies for diagnostic evaluation of symptoms. Currently, over 500 000 colonoscopies are performed each year in Australia, mostly in adults aged 50-74 
years. ${ }^{30}$ If these procedures are accounted for when assessing screening status, and therefore program eligibility, the need for additional FOBT and colonoscopies will be lower, with consequently lower incremental spending. If $20 \%$ of the estimated 75000 annual colonoscopies are already occurring outside the screening program, then the actual additional cost of fully implementing the program may be almost $\$ 20$ million less per year (15 000 fewer procedures at $\$ 1300$ each). If efforts are made to promote adherence to NHMRC guidelines for surveillance, colonoscopy costs may be further reduced, and available capacity increased, through reducing unnecessary use of surveillance examinations. ${ }^{31,32}$

Accounting for these factors and including the current federal government investment in CRC screening (\$29 million per year), it is likely that the additional investment required to fully implement screening would be less than $\$ 50$ million per year (Box 3).

3 Cost offsets and effect on investment required

\section{Cost offsets}

- Reduction in colorectal cancer incidence with screening and surveillance, 5\%$10 \%{ }^{27}$

$>$ potential annual savings: \$27-\$45 million

- Effect of stage-shifting on cost (net 10\% cancers from Stage D to Stage A*)29

$>\quad$ potential annual savings: \$27 million

- Cost of colonoscopy complications (1 per 1000 colonoscopies with cost of $\$ 15$ 000 per incident)

$>$ potential annual additional costs: $\$ 1.1$ million

- Net effect: reduction in cost of \$53-\$71 million annually

\section{Costs currently paid in other health sectors}

- Reduction in colonoscopy resources needed as a result of existing ad-hoc screening

$$
>\quad \text { if } 20 \% \text {, would reduce funds required by about } \$ 20 \text { million annually }
$$

- Current annual spending on screening program: $\$ 29$ million

- Total screening costs currently paid in other sectors: $\$ 49$ million

\section{Estimate of additional investment required}

- Total estimated gross cost: $\$ 150$ million

- Savings from cost offsets: \$53-\$71 million

- Current spending: $\$ 49$ million

- Total additional investment required: $\$ 30-\$ 48$ million

* Staging according to the Dukes classification.

\section{DISCUSSION}

Our review of existing models of CRC screening in Australia suggests that a program of biennial iFOBT screening in adults aged 50-74 years is likely to be effective, preventing $300-500$ deaths annually, and cost-effective, with costs per LYG generally less than $\$ 50$ 
000. To date, government budgeting constraints and concern about capacity, particularly the availability of colonoscopy, have led to the adoption of a limited program of one-time screening for adults aged 50, 55 and 65 years. ${ }^{10}$ At present, funding for even this limited program is due to expire in mid 2011 unless it is reauthorised.

Given the increasing costs of treating advanced CRC, our updated modelling suggests that the implementation of full biennial screening is affordable, with gross annual costs of $\$ 150$ million offset by $\$ 50$ million or more in savings from reduced cancer incidence and shifting of diagnosed cancers to more favourable stages that are less expensive to treat. After accounting for the current rate of colonoscopies performed outside the screening program and the current federal government screening program investment, the actual additional expenditure required is likely to be less than $\$ 50$ million per annum.

Our estimates of total gross program costs are similar to those from previous models, ${ }^{14,25}$ and these costs would be similar to or less than current investment in screening programs for breast cancer ( $\$ 120$ million in the 2006-07 financial year) ${ }^{33}$ and cervical cancer $(\$ 140$ million in 2001). ${ }^{34}$ One US analysis has found that investment in CRC screening is among the most valuable of all preventive services. ${ }^{35}$

In addition to the political and institutional constraints on the development of an evidencebased bowel cancer screening program, ${ }^{10}$ budgetary constraints and concerns about the adequacy of Australia's capacity for diagnostic colonoscopy and cancer treatment are factors that have acted as barriers to the expansion of the program. Our analysis suggests that total government spending would increase only modestly if the program were expanded to biennial screening of Australian residents aged 50-74 years. The largest cost component is that of colonoscopy, determined by both the unit cost of the procedure and the total number of procedures performed. Efforts to control the unit cost of colonoscopy while maintaining quality, ${ }^{31}$ and to reduce the overuse of colonoscopy for surveillance, ${ }^{32}$ are important for ensuring program value.

Concerns about the capacity to perform colonoscopy relate mainly to public-sector capacity, and could be mitigated through a preferred provider voucher program that would allow screening program participants to have colonoscopies in public or private settings for a negotiated fixed cost and with the assurance of quality and safety. ${ }^{18}$ The recent high growth rates in colonoscopy procedures suggest that private-sector colonoscopy facilities are able to meet the additional demand for services. ${ }^{30}$ Reductions in the overuse of colonoscopy for surveillance or for ad-hoc screening will also help in this regard.

A limitation of our analysis has been a paucity of data for several key parameters, particularly the number of colonoscopies required in a full program of screening and surveillance. There are also insufficient data to estimate the effectiveness or costeffectiveness of the current one-time screening program at ages 50, 55 and 65 years; or that of alternative options to iFOBT, including gFOBT, flexible sigmoidoscopy, or colonoscopy. We focused on iFOBT because the government has selected it for the national screening program, and because recent data suggest it may perform better than some other options. ${ }^{36}$

Our modelling did not examine the full consequences of screening in terms of discounted quality-adjusted life-years, but its findings are consistent with other, more sophisticated models, giving us increased confidence in its results. The application of more sophisticated models may be warranted as additional evidence emerges. 


\section{Conclusion}

Consistent evidence suggests that screening for bowel cancer with biennial iFOBT in Australians aged 50-74 years is both effective (preventing an estimated 300-500 deaths from bowel cancer each year) and cost-effective. The rising costs of treating advanced bowel cancer make screening even more compelling. Based on savings from reduced treatment costs, we estimate that implementation of a full program could be achieved with a modest additional investment that would bring spending on the program up to a level similar to that for other cancer screening programs. At present, the bowel cancer screening program has not been funded beyond mid 2011. It is our hope that our analysis will provide relevant information for government decisionmakers to weigh the potential benefits and costs of a full program versus other spending priorities.

\section{Acknowledgments}

This work was funded by the Australian Government Department of Health and Ageing and the United States National Cancer Institute (grant no. K05 CA129166, Pignone PI).

\section{REFERENCES}

1. Australian Institute of Health and Welfare. The twelfth biennial health report of the Australian Institute of Health and Welfare. Canberra: AIHW; 2010. Australia's health 2010. Australia's health series no. 12. (AIHW Cat. No. AUS 122.)http://www.aihw.gov.au/publications/aus/ah10/ah10.pdf

2. Australian Institute of Health and Welfare and Australasian Association of Cancer Registries. 2008. Canberra: AIHW; Cancer in Australia: an overview, 2008. Cancer series no. 46. (AIHW Cat. No. CAN 42.)http://www.aihw.gov.au/publications/can/ca08/ca08.pdf

3. GLOBOCAN. Cancer fact sheet. Colorectal cancer incidence and mortality worldwide in 2008. 2008 http://globocan.iarc.fr/factsheets/cancers/colorectal.asp.

4. Begg SJ, Vos T, Barker B, et al. Burden of disease and injury in Australia in the new millennium: measuring health loss from diseases, injuries and risk factors. Med J Aust. 2008; 188:36-40. [PubMed: 18205562]

5. Australian Institute of Health and Welfare. Canberra: AIHW; 2005. Health system expenditures on cancer and other neoplasms in Australia, 2000-01. Health and welfare expenditure series no. 22. (AIHW Cat No. HWE 29.) http://www.aihw.gov.au/publications/hwe/hsecna00-01/hsecna00-01.pdf

6. Towler B, Irwig L, Glasziou P, et al. A systematic review of the effects of screening for colorectal cancer using the faecal occult blood test, hemoccult. BMJ. 1998; 317:559-565. [PubMed: 9721111]

7. Atkin WS, Edwards R, Kralj-Hans I, et al. UK Flexible Sigmoidoscopy Trial Investigators. Onceonly flexible sigmoidoscopy screening in prevention of colorectal cancer: a multicentre randomised controlled trial. Lancet. 2010; 375:1624-1633. [PubMed: 20430429]

8. Benson VS, Patnick J, Davies AK, et al. International Colorectal Cancer Screening Network. Colorectal cancer screening: a comparison of 35 initiatives in 17 countries. Int J Cancer. 2008; 122:1357-1367. [PubMed: 18033685]

9. Australian Cancer Network Colorectal Cancer Guidelines Revision Committee. Sydney: The Cancer Council Australia and Australian Cancer Network; 2005. Clinical practice guidelines for the prevention, early detection and management of colorectal cancer. http://www.nhmrc.gov.au/_files_nhmrc/file/publications/synopses/cp106/cp106.pdf

10. Flitcroft KL, Salkeld GP, Gillespie JA, et al. Fifteen years of bowel cancer screening policy in Australia: putting evidence into practice? Med J Aust. 2010; 193:37-42. [PubMed: 20618113]

11. Pignone M, Saha S, Hoerger T, Mandelblatt J. Cost-effectiveness analyses of colorectal cancer screening: a systematic review for the US Preventive Services Task Force. Ann Intern Med. 2002; 137:96-104. [PubMed: 12118964]

12. OECD StatExtracts [website]. [accessed Dec 2010] Prices and purchasing power parities. Purchasing power parities (PPP) statistics. Purchasing power parities for GDP and related indicators. http://stats.oecd.org/Index.aspx?DataSetCode=PPPGDP 
13. Australian Institute of Health and Welfare. Canberra: AIHW; 2009. Australia's health expenditure 2007-2008. Health and welfare expenditure series no.

37.http://www.aihw.gov.au/publications/hwe/hwe-46-10954/hwe-46-10954.pdf

14. Bishop, J.; Glass, P.; Tracey, E., et al. Cancer Institute NSW monograph. Sydney: Cancer Institute NSW; 2008. Health economics review of bowel cancer screening in Australia. http://www.cancerinstitute.org.au/cancer_inst/publications/pdfs/2008-08-28_monograph-bowelcancer-screening-in-australia.pdf

15. Australian Institute of Health and Welfare and Australian Government Department of Health and Ageing. Annual monitoring report 2009. Canberra: AIHW; 2009. National Bowel Cancer Screening Program. Cancer series no. 49. (AIHW Cat. No. CAN 45.)http://www.aihw.gov.au/publications/can/can-45-10752/can-45-10752.pdf

16. Queensland Health. Brisbane: Queensland Health; 2009. Queensland bowel cancer screening program. Phase 1: evaluation; 7 August 2006 - 30 June 2008.

17. Burnet NG, Jefferies SJ, Benson RJ, et al. Years of life lost (YLL) from cancer is an important measure of population burden - and should be considered when allocating research funds. $\mathrm{Br} \mathrm{J}$ Cancer. 2005; 92:241-245. [PubMed: 15655548]

18. United States National Institutes of Health. Cancer trends progress report - 2009/2010 update. Bethesda, Md: National Cancer Institute; 2010. National Cancer Institute. http://progressreport.cancer.gov/doc_detail.asp?pid=1\&did=2009\&chid=96\&coid=930\&mid=

19. McDermid, I. Canberra: Australian Institute of Health and Welfare, Australasian Association of Cancer Registries and the National Cancer Strategies Group; 2005. Cancer incidence projections, Australia 2002 to 2011. http://www.aihw.gov.au/publications/can/cipa02-11/cipa02-11-c00.pdf

20. Lansdorp-Vogelaar I, van Ballegooijen M, Zauber AG, et al. Effect of rising chemotherapy costs on the cost savings of colorectal cancer screening. J Natl Cancer Inst. 2009; 101:1412-1422. [PubMed: 19779203]

21. Jonas DE, Russell LB, Sandler RS, et al. Value of patient time invested in the colonoscopy screening process: time requirements for colonoscopy study. Med Decis Making. 2008; 28:56-65. [PubMed: 18263561]

22. Salkeld G, Young G, Irwig L, et al. Cost-effectiveness analysis of screening by faecal occult blood testing for colorectal cancer in Australia. Aust N Z J Public Health. 1996; 20:138-143. [PubMed: 8799087]

23. Stone CA, Carter RC, Vos T, St John J. Colorectal cancer screening in Australia: an economic evaluation of a potential biennial screening program using faecal occult blood tests. Aust N Z J Public Health. 2004; 28:273-282. [PubMed: 15707175]

24. O'Leary BA, Olynyk JK, Neville AM, Platell CF. Cost-effectiveness of colorectal cancer screening: comparison of community-based flexible sigmoidoscopy with fecal occult blood testing and colonoscopy. J Gastroenterol Hepatol. 2004; 19:38-47. [PubMed: 14675241]

25. Graves N, McKinnon L, Leggett B, Newman B. Re-interpreting the data on the cost and effectiveness of population screening for colorectal cancer in Australia. Aust N Z Health Policy. $2005 ; 2: 10$.

26. Bolin TD, Korman MG, Stanton R, et al. Positive cost effectiveness of early diagnosis of colorectal cancer. Colorect Dis. 1999; 1:113-122.

27. Mandel JS, Church TR, Bond JH, et al. The effect of fecal occult-blood screening on the incidence of colorectal cancer. N Engl J Med. 2000; 343:1603-1607. [PubMed: 11096167]

28. Howard DH, Kauh J, Lipscomb J. The value of new chemotherapeutic agents for metastatic colorectal cancer. Arch Intern Med. 2010; 170:537-542. [PubMed: 20233802]

29. Ananda SS, McLaughlin SJ, Chen F, et al. Initial impact of Australia's National Bowel Cancer Screening Program. Med J Aust. 2009; 191:378-381. [PubMed: 19807627]

30. The National Bowel Cancer Screening Program Quality Working Group. Canberra: Australian Government Department of Health and Ageing; 2009. Improving colonoscopy services in Australia. http://www.cancerscreening.gov.au/internet/screening/publishing.nsf/Content/ 3FD09B61D2B4E286CA25770 B007D1537/\$File/Improving\%20col\%20serv 0709.pdf 
31. Bampton PA, Sandford JJ, Young GP. Applying evidence-based guidelines improves use of colonoscopy resources in patients with a moderate risk of colorectal neoplasia. Med J Aust. 2002; 176:155-157. [PubMed: 11913914]

32. Yusoff IF, Hoffman NE, Ee HC. Colonoscopic surveillance for family history of colorectal cancer: are NHMRC guidelines being followed? Med J Aust. 2002; 176:151-154. [PubMed: 11913913]

33. BreastScreen Australia evaluation. Screening Monograph No.1. Canberra: Australian Government Department of Health and Ageing; 2009. Evaluation Final Report 2009. http://www.cancerscreening.gov.au/internet/screening/publishing.nsf/Content/ 8463830B90E5BDF5CA 25762A000193C6/\$File/Cover\%20contents.pdf

34. Anderson R, Haas M, Shanahan M. The cost-effectiveness of cervical screening in Australia: what is the impact of screening at different intervals or over a different age range? Aust $\mathrm{N} Z \mathrm{~J}$ Public Health. 2008; 32:43-52. [PubMed: 18290913]

35. Maciosek MV, Solberg LI, Coffield AB, et al. Colorectal cancer screening: health impact and cost effectiveness. Am J Prev Med. 2006; 31:80-89. [PubMed: 16777546]

36. Hol L, van Leerdam ME, van Ballegooijen M, et al. Screening for colorectal cancer: randomised trial comparing guaiac-based and immunochemical faecal occult blood testing and flexible sigmoidoscopy. Gut. 2010; 59:62-68. [PubMed: 19671542] 